\title{
Evaluation of Platelet Parameters in Patients of Acute Myocardial Infarction
}

Nanda Patil ${ }^{1}$, Sujata R. Kanetkar ${ }^{2}$, Garima Agarwal ${ }^{3 *}$

${ }^{1}$ Professor, Department of Pathology, Krishna Institute of Medical Sciences Deemed to be University, Karad

${ }^{2}$ Professor and Head, Department of Pathology, Krishna Institute of Medical Sciences Deemed to be University, Karad

${ }^{3}$ Tutor, Department of Pathology, Krishna Institute of Medical Sciences Deemed to be University, Karad

DOI: $\underline{10.36347 / \text { simcr.2020.v08i06.005 }}$

| Received: 20.05.2020 | Accepted: 31.05 .2020 | Published: 16.06 .2020

*Corresponding author: Dr. Garima Agarwal

Abstract

Original Research Article

Myocardial infarction is among the top five causes of morbidity worldwide and is increasingly becoming common in India. Myocardial infarction depicts acceleration of atherosclerotic process accompanied by a cascade of platelet reactions resulting into formation of thrombus. It is likely that different individuals have platelets of variable size, density and reactivity; larger platelets aggregate more rapidly with subendothelial collagen and lead to thrombosis and subsequently acute myocardial infarction. It is possible to measure platelet parameters i.e. mean platelet volume (MPV), platelet distribution width (PDW) and platelet count (PC) with electronic cell counters. Recognition of platelet parameters as a risk factor in acute myocardial infarction will help to reduce the morbidity and mortality in cases of acute myocardial infarction. The current study involves evaluation of platelet parameters (MPV, PDW \& PC) as the risk factor in patients with acute myocardial Infarction during the period of 6 months from September 2018 to February 2019.

Keywords: Myocardial infarction, Platelet parameter.

Copyright @ 2020: This is an open-access article distributed under the terms of the Creative Commons Attribution license which permits unrestricted use, distribution, and reproduction in any medium for non-commercial use (NonCommercial, or CC-BY-NC) provided the original author and source are credited.

\section{INTRODUCTION}

Myocardial infarction is among the top five causes of morbidity worldwide and is increasingly becoming common in India as well. The underlying pathology of myocardial infarction is atherosclerosis, which progresses clinically to manifest as myocardial infarction usually in fifth and sixth decades of life.

Myocardial infarction depicts acceleration of atherosclerotic process accompanied by a cascade of platelet reactions resulting into formation of thrombus.

Platelets are known to play a critical role in conversion of chronic atherosclerotic plaque into an occluding thrombus [1]. The thrombus leads to partial or complete coronary artery occlusion, which in turn, results in myocardial infarct. It is likely that different individuals have platelets of variable size, density and reactivity [2]. Larger the platelets, they are more likely to be metabolically and enzymatically active. Large platelets are denser, aggregate more rapidly with subendothelial collagen, produce more thromboxane A2 and express more glycoprotein $\mathrm{Ib}$ and glycoprotein IIb/IIIA receptors $[3,4]$. These characteristics may lead to increase thrombosis and possibly acute myocardial infarction.

Electronic cell counters have made it possible to measure platelet volume indices that are mean platelet volume (MPV), platelet distribution width (PDW). This is a simple and cost effective method of identifying these larger platelets. The current study is planned to evaluate MPV, PDW and PC as the risk factors in patients with an incident of acute myocardial infarction.

\section{AIM \& OBJECTIVES}

To measure platelet parameters (MPV,PDW \& Platelet count) in patients with acute myocardial infarction and to compare the values with those of age and sex matched controls and with cardiac markers.

\section{Material ANd Methods}

A 6 months analytical study of platelet parameters (MPV, PDW and PC) was carried out in the hematology unit of department of pathology in our institute from September 18 to February 19. 
Patients, with clinically diagnosed acute myocardial infarction were taken as cases. Age and sex matched patients, admitted for elective surgical procedures, with normal ECG and without any history of AMI in previous 2 years were taken as controls. Blood samples of cases were collected within 24 hours of onset of symptoms. Blood samples (of both cases and controls) were collected aseptically in EDTA vacutainer and were analysed with a 5-part automated hematology analyser, within 30 minutes of sample collection.

Value of platelet parameters, of both, cases as well as controls were recorded immediately. Findings of platelet parameters were confirmed with peripheral smear. Data regarding age, sex and $\mathrm{P}$ values were documented. The data were compared between cases and controls. Association between platelet parameters and AMI were carried out. 75 cases and 75 controls were taken for the study.

Patients on antiplatelet therapy were excluded. The study was conducted after ethical clearance from our institute.

\section{Observations}

The study of platelet parameters in cases of MI was carried out for a period of 6 months in the hematology unit of department of pathology in our institute from September 18 to February 19. This included 75 patients as cases (Group 1) and equal number of age and sex matched controls (Group 2).

In the study, majority of patients (30 patients,i.e.40\%) belonged to 51-60 years age group, followed by 23 patients $(30.7 \%)$, belonged to $61-70$ age group

Table-1: Age wise distribution of cases

\begin{tabular}{|c|c|c|}
\hline Age (Years) & \multicolumn{2}{|c|}{ Cases $(\mathbf{n = 7 5})$} \\
\hline & Number & $\%$ \\
\hline $31-40$ & 7 & 9.3 \\
\hline $41-50$ & 12 & 16 \\
\hline $51-60$ & 30 & 40 \\
\hline $61-70$ & 23 & 30.7 \\
\hline$>70$ & 3 & 4 \\
\hline & 75 & 100 \\
\hline
\end{tabular}

- $\quad$ There was no patient in $<30$ age group with MI. Youngest patient in Group I (Cases) was a 37 years old male, while oldest was a 75 years old male, the mean age being 56 years.

- Male preponderance was seen in the present study, i.e., 51 males (68\%) against 24 females $(32 \%)$

Table-2: Distribution of risk factors in patients with MI

\begin{tabular}{|c|c|c|}
\hline Risk factors & No. of patients & \% \\
\hline Diabetes & 54 & 72 \\
\hline Obesity & 32 & 42 \\
\hline Alcohol & 26 & 34.7 \\
\hline Hypertension & 17 & 23 \\
\hline Positive family history & 4 & 5 \\
\hline Tobacco consumption & 9 & 12 \\
\hline
\end{tabular}

Major risk factors in the present study were diabetes (72\%), obesity (42\%) and alcohol (34.7\%).

Table-3: Distribution of presenting symptoms

\begin{tabular}{|c|c|c|}
\hline Symptoms & Number of patients & Percentage of patients \\
\hline Chest pain & 72 & $96 \%$ \\
\hline Sweating & 56 & $75 \%$ \\
\hline Breathlessness & 40 & $53 \%$ \\
\hline Giddiness & 26 & $35 \%$ \\
\hline Palpation & 21 & $28 \%$ \\
\hline Vomiting & 16 & $21 \%$ \\
\hline
\end{tabular}

In the present study, most of the patients presented with multiple symptoms. The commonest presenting symptoms were chest pain $(96 \%)$, followed by sweating $(74 \%)$ and breathlessness $(54 \%)$.

\section{Platelet volume indices \\ Mean Platelet Volume}

The platelet parameters, which were taken into account in the study, were Mean Platelet Volume (MPV), Platelet distribution Width (PDW) and Platelet Count (PC).
Values of platelet parameters were compared between that of cases and controls.

The value of MPV was found to be statistically significant in cases when compared to controls. Comparing the mean of 2 groups (Cases vs controls), $t$ test showed significant difference $(p<0.05)$ and higher MPV. 
- Mean MPV of cases was $11.52 \mathrm{fl}$ and of control was $9.09 \mathrm{fl}$. This was statistically significant (p value -0.0001 )

- Mean MPV of females (11.57 fl) was higher than in males $(11.30 \mathrm{fl})$

- Mean MPV was higher in post-menopausal women (11.61 fl) then pre-menopausal women $(10.83 \mathrm{fl})$.

\section{Platelet distribution width}

A significantly higher PDW was observed in acute myocardial infarction patients when compared to controls.

The mean value of PDW in cases was found $10.43 \mathrm{fl}$, while that of controls, it was found $9.92 \mathrm{fl}$ and showed statistically significant $\mathrm{p}$ value $(\mathrm{p}<0.05)$.

\section{Platelet count}

Acute myocardial infarction cases had lower mean value for platelet count (2.61 lacs/cumm) than those of controls (2.73 lacs/cumm). The t test showed no significant difference between cases and controls $(\mathrm{p}=0.097)$.

\section{Comparison of platelet parameters between cases \& controls}

Comparison of MPV \& PDW between MI and controls showed statistically significant $(p<0.05)$ increase in both of the platelet parameters in MI cases. The mean values of platelet count (PC) in patients with MI showed slight decrease in its value, when compared with those of controls. Also, no significant difference existed.

Table-4: Comparison of platelet parameters between MI and controls

\begin{tabular}{|c|c|c|c|}
\hline & MI & Controls & p value \\
\hline No. of patients & 75 & 75 & \\
\hline MPV & 11.52 & 9.09 & $<0.001$ \\
\hline PDW & 10.43 & 9.92 & 0.008 \\
\hline PC & 2.61 & 2.73 & 0.228 \\
\hline
\end{tabular}

\section{Correlation with cardiac biomarkers}

- Amongst 75 cases of MI, Troponin I levels were increased in 47 patients $(63 \%)$ and in the remaining 28 patients, Troponin I were within normal limits.

- The mean values of MPV in CK-MB positive MI cases, CK-MB negative cases and controls were found to be $11.65 \mathrm{fl}, 11.31 \mathrm{fl}$ and $9.09 \mathrm{fl}$ respectively. Thus, the mean value of MPV was found higher in CK-MB positive MI cases than in CK-MB cases as well as controls.

\section{DISCUSSION}

Coronary heart disease increases with increasing age and the risk of MI increases 5 fold between 40-60 years [5]. The MI is higher in men than premenopausal women. This risk increases in postmenopausal women [5]. Diabetes and hypertension have greater relative effects on risk of acute myocardial infarction in younger individuals [6].

Atherosclerosis is an inflammatory condition. Platelets are also now considered as cells involved in both thrombosis and inflammation [7-9].

Platelets and leucocytes play an important role in the development, maturation and progression of an atherosclerotic lesion.

\section{Conclusion}

- Larger platelets are hemostatically more active, the presence of larger platelets is probably a risk factor for developing myocardial infarction.

- Patients with larger platelets can easily be identified during routine hematological analysis, as
MPV \& PDW are generated as a byproduct of automated blood counts.

- Thus, these indices are considered as a cost effective tool which predict an atherosclerothrombotic tendency in human body.

\section{ACKNOWLEDGMENTS}

The authors would like to acknowledge Krishna Institute of Medical Sciences deemed to be University, Karad for allowing the study to carry out by providing the necessary resources, research department for sanctioning the project and providing necessary guidance and the hospital laboratory technicians for their cooperation in sample collection and processing.

\section{Author contributions}

All authors contributed toward data analysis, drafting and revising the article and agree to be accountable for all aspects of the work.

\section{Disclosure}

The authors report no conflicts of interest in the article work and its publication.

\section{REFERENCES}

1. Trip MD, Cats VM, van Capelle FJ, Vreeken J. Platelet hyperreactivity and prognosis in survivors of myocardial infarction. New England Journal of Medicine. 1990 May 31;322(22):1549-54.

2. Karpatkin S. Heterogeneity of human platelets: II. Functional evidence suggestive of young and old platelets. The Journal of clinical investigation. 1969 Jun 1;48(6):1083-7. 
3. Corash L, Tan H, Gralnick HR. Heterogeneity of human whole blood platelet subpopulations. I. Relationship between buoyant density, cell volume, and ultrastructure.

4. Khandekar MM, Khurana AS, Deshmukh SD, Kakrani AL, Katdare AD, Inamdar AK. Platelet volume indices in patients with coronary artery disease and acute myocardial infarction: an Indian scenario. Journal of clinical pathology. 2006 Feb 1;59(2):146-9.

5. Davidson CM. Angina and heart attacks (understanding). Poole: Family Doctor Publications in association with the British Medical Association; 2006.

6. Yusuf S, Hawken S, Ôunpuu S, Dans T, Avezum A, Lanas F, McQueen M, Budaj A, Pais P, Varigos
J, Lisheng L. Effect of potentially modifiable risk factors associated with myocardial infarction in 52 countries (the INTERHEART study): case-control study. The lancet. 2004 Sep 11;364(9438):937-52.

7. Stokes KY, Granger DN. Platelets: a critical link between inflammation and microvascular dysfunction. The Journal of physiology. 2012 Mar 1;590(5):1023-34.

8. Lam FW, Vijayan KV, Rumbaut RE. Platelets and their interactions with other immune cells. Comprehensive Physiology. 2011 Jan 17;5(3):1265-80.

9. Franco AT, Corken A, Ware J. Platelets at the interface of thrombosis, inflammation, and cancer. Blood, The Journal of the American Society of Hematology. 2015 Jul 30;126(5):582-8. 